\title{
Cervical and Oral Screening for HR-HPV types 16 and 18 among Sudanese Women Cervical Lesions
}

\author{
Abdelbaset Mohamed Elasbali ${ }^{*}$, Afra Hassan Saad El Din², Rania Abdeen Hussein Abdallah ${ }^{3}$ \\ and Hussain Gadelkarim Ahmed ${ }^{1}$
}

\begin{abstract}
Objective: This study examined whether there is a positive correlation existed between cervical and oral High Risk-Human Papilloma Viruses (HR-HPV) types 16, 18 infections in patients with clinically confirmed cervical lesions.

Methods: In this study 50 participants were included (40 were cases and 10 were controls). One hundred DNA materials (50 were cervical and 50 were oral epithelial tissues) were analyzed using HR-HPV subtypes 16 and 18 specific PCR probes.

Results: Of the 40 cases, HR-HPV 16, 18 were identified in 16/40 (40\%), of the cervical tissues of whom 8/16 (50\%) were positive for HPV 16; 6/16 (37.5\%) were identified with HR-HPV 18, and 2/16 (12.5\%) were detected with both HR-HPV subtypes. All of the clinically healthy cases were found negative. Only one oral tissue sample (case) was 1/ 40 (2.5\%) was found positive for HPV subtype16.

Conclusion: The frequency of infection with HR-HPV subtypes 16 and 18 is high among Sudanese women with cervical lesions and suggests a role of HR-HPV in the development of cervical cancer in Sudan. No correlation between cervical and oral HPV infection was noted. Further study with screening of large number of patients with cervical cancer is recommended for further clarification of these findings.
\end{abstract}

Keywords: HR -HPV 16, 18, Cervical lesions, Sudanese

\section{Introduction}

Cervical cancer is the second most common cancer found in women with approximately 530,000 new cases each year resulting in an estimated 275,000 deaths, worldwide. In developed countries, cervical cancer incidences have declined, mostly due to cervical cytology screening campaigns, which requires significant medical resources and laboratory infrastructure. Cervical cancer is on the rise in the developing world, with one-seventh of the world's cervical cancer cases in China, where no nationwide screening program for the disease currently exists [1]. In Sudan, cervical cancer is the second most common cancer type among women [2] and there are 923 new cases representing 4.5/100,000 [3]. The researchers have proposed that Human Papilloma Viruses (HPV) testing of self-collected Pap specimens

\footnotetext{
* Correspondence: elasbali2000@hotmail.com

${ }^{1}$ Department of Histopathology and cytology, University of Khartoum, Khartoum, Sudan

Full list of author information is available at the end of the article
}

might serve as an alternative or complementary method of a primary cervical cancer screening method [1]. As long ago as 1995 the causative association between HPV and Squamous Cell Carcinoma (SCC) was recognized [4]. Epidemiological studies demonstrated that the major risk factor for the development of pre-invasive and invasive carcinoma of the cervix is HPV infection. In an international study consisting of 1000 specimens from patients with invasive cancer in 32 hospitals in 22 countries ,HPV-DNA was present in $99.7 \%$ of cervical cancers, HPV16 was the predominant type in all countries except Indonesia where type 18 was more common[5]. HPVs are small, non-enveloped DNA viruses. HPV infects and replicate within cutaneous and mucosal epithelial tissues. The HPV family of viruses contains more than 100 types. Approximately $40 \mathrm{HPV}$ types affect the genital area. They can be sub-divided into low risk for cervical cancer and high risk [6]. The high risk are associated with the development of cervical cancer includes (types 16, 18, 31, 33, 35, 39, 45, 51, 52, 56, 58, 59, 68, 73, 
82) [7]. The low-risk types (HPV 6, 11, 40, 42, 43, 44, 54, 61, 70, 72, 81, and CP6108) can cause mild cervical dysplasia but are rarely associated with severe cervical dysplasia or cervical carcinoma $[8,9]$.

HPV infection has also been postulated as a potential risk factor for OSCC. Several studies have detected HPV DNA in a considerable proportion of oral cancers, with wide variations from $0 \%$ to $100 \%$ prevalence in oral tissues, perhaps reflecting the inherent variations in the different populations, [10-12].

In Sudan, invasive cervical cancer is a leading cause of cancer death among women [13] . Most cervical cancers are squamous cell carcinomas representing 90.9\%, followed by adenocarcinomas $4.8 \%$, and other epithelial tumors were $4.3 \%$. Of the squamous carcinomas, $98.8 \%$ were invasive and $1.2 \%$ intraepithelial (cervical intraepithelial neoplasia). The majority of cases presenting with a protruding cervical mass [14]. Although there are many suggested risk factors for cervical cancer [15], HPV remains the prime suspect.

Furthermore, a recent study has reported strong association between HPV types 16 and 18 and OSCC, although, some prior studies have reported a lack [16] or low association between HPV and OSCC among Sudanese patients [17].

However, due to the lack of published data from Sudan in this context, the aim of this study is to examine whether there is a positive correlation existed between cervical and oral HR-HPV types 16, 18 infections in patients with clinically confirmed cervical lesions.

\section{Materials and methods}

\section{Study design}

In this descriptive study, 40 patients with clinically confirmed cervical lesions (cases) 10 clinically confirmed with no cervical lesions (controls) were investigated for the presence of HR-HPV subtypes 16 and 18 PCR using molecular techniques. All subjects were randomly selected from those referred to gynecologic clinic at Al Nou hospital. All Participants were with apparently healthy oral cavity.

\section{Ethical consent}

The study was approved by the ethics board of the Faculty of Medical Laboratory Science, Sudan University for Science and Technology. All cervical samples were taken as a part of the specimens required for investigation. All study subjects were consented to participation by completing the self-administered questionnaire.

\section{Sample processing}

The sample size represents a full coverage of patients that were referred to the gynecologic clinic and agreed to participate within 6 months period. One hundred samples (50 cervical scrapes and 50 oral scrapes) were collected as a part of the specimen required for screening for cervical cancer. Both cervical and oral cells were obtained from the same person and processed similarly. B scraped cells placed in sterile Caryo-tube containing $5 \mathrm{ml}$ Tris- $\mathrm{HCl}$ buffer ( $\mathrm{PH}$ 8.0) (preparation stock A 2.42 gm Tris in $100 \mathrm{~cm} 3$ of distill water, stock B $1.7 \mathrm{~cm} 3$ hydrochloric acid in $100 \mathrm{~cm} 3$ distill water, $25 \mathrm{~cm} 3$ of A +13.4 of B made up to $100 \mathrm{~cm} 3$ with distill water). The components were then centrifugated and the supernatant was discarded, and the deposit was kept immediately in the refrigerator in $-200 \mathrm{C}$.

\section{DNA extraction}

DNA was extracted according to the steps described in DNA extraction kit purchased from Sacace biotechnologiesCasera - Italy. The pellet obtained from previous steps was treated with $300 \mu \mathrm{l}$ of Reagent 2 (lysis buffer) in addition $100 \mu \mathrm{l}$ of sample, vortexed, incubated at $65^{\circ} \mathrm{C}$ for $5 \mathrm{~min}$ and centrifuged at (12000-16000 g) for $10 \mathrm{~min}$ and transfer the supernatant into new tube (sterile $1.5 \mathrm{ml}$ Eppendorf tube) for DNA extraction . Vortexed vigorously sorbent and added $20 \mu \mathrm{l}$ to each tube, Vortexed for 5-7 sec and incubated all tubes for $3 \mathrm{~min}$ at room temperature, then this step was repeated. Then all tubes were centrifugated for $30 \mathrm{sec}$ at $5000 \mathrm{~g}$ and used amicropipette with aplugged aerosol barrier tip, carefully removed and discarded supernatant from each tube without disturbing the pellet. Tips was Changed between the tubes. $500 \mu \mathrm{l}$ of Washing Solution was added to each tube. Vortexed vigorously and centrifuged for $30 \mathrm{sec}$ at 10000 g. Supernatant was removed and discarded from each tube. This step was repeated and incubated all tubes with open cap for $5-10 \mathrm{~min}$ at $65^{\circ} \mathrm{C}$. The pellet was resuspended in $100 \mu \mathrm{l}$ of DNA-eluent. Incubate for $5 \mathrm{~min}$ at $65^{\circ} \mathrm{C}$ and vortex periodically. The tubes were centrifuged for $1 \mathrm{~min}$ at 12000x g. The supernatant was containing DNA ready for amplification stored at $-20^{\circ} \mathrm{C}$ until used.

\section{Polymerase chain reaction (PCR) Amplification of HPV}

Type specific primers (primer for HPV 16 and HPV18) were used to detect HPV16 and 18 DNA in oral benign and malignant lesion. Amplification was performed according to HPV16/18 kit from Sacace-Biotechnologies S.r.l. Caserta -Italy. The final reaction volume of $40 \mu \mathrm{l}$ containing $20 \mu \mathrm{l}$ mix-1 (contained in PCR tubes), $10 \mu \mathrm{l}$ of mix-2 and $10 \mu \mathrm{l}$ of extracted DNA (sample). Negative control, positive HPV16 DNA and positive control 18 DNA tubes contained $10 \mu \mathrm{l}$ of DNA buffer, $10 \mu \mathrm{l}$ of HPV 16 DNA and10 $\mu$ l of HPV18 DNA respectively. Samples and controls were amplified using Gene Amp PCR system 9700. The PCR program is described in Table 1.

\section{Gel-electrophoresis}

The PCR products were visualized in $2 \%$ Agarose gel with $0.5 \mu \mathrm{g} / \mathrm{ml}$ Ethidium bromide. Ten micro liters of 
Table 1 PCR steps

\begin{tabular}{cccc}
\hline Cycles & Time & Tem & PCR steps \\
\hline Pause & & $95^{\circ} \mathrm{C}$ & 0 \\
1 & $5 \mathrm{~min}$ & $95^{\circ} \mathrm{C}$ & 1 \\
42 & $15 \mathrm{sec}$ & $95^{\circ} \mathrm{C}$ & 2 \\
& $25 \mathrm{sec}$ & $65^{\circ} \mathrm{C}$ & \\
& $25 \mathrm{sec}$ & $72^{\circ} \mathrm{C}$ & 3 \\
1 & $1 \mathrm{~min}$ & $72^{\circ} \mathrm{C}$ & 4 \\
\hline
\end{tabular}

100 bp DNA ladder and PCR product was loaded on the gel. Gel-electrophoresis was performed at $120 \mathrm{~V}$ and $36 \mathrm{~mA}$ for 60 minutes. Pictures were taken by Gel documentation system (Gel mega, digital camera and software in a computer).

\section{Interpretation of PCR results}

According to manufacture HPV16/18 kit (Sacace-Biotechnologies S.r.l. Caserta -Italy) manual, the PCR product length for HPV16 should be $325 \mathrm{bp}$ and 425 bp for HPV18.

\section{Data analysis}

Data management was done by using the Statistical Package for Social Sciences (SPSS version 12; SPSS Inc, Chicago, IL). SPSS was used for analysis and to perform Fisher exact test for statistical significance ( $\mathrm{P}$ value $<0.05$ was considered significant). The $95 \%$ confidence level and confidence intervals were used.

\section{Results}

A total of 40 cases (patients with clinically confirmed cervical lesions) and 10 controls (patients without cervical lesions) were included in this study. The age distribution is relatively similar between cases and controls with a range of 18 to 70 years and a mean age of 33 years. Most of cases were middle age 26-35 years representing 21/40 (52.5\%) followed by 18-25 group 8/ $40(20 \%)$, as indicated in Table 2, Figure 1. The distribution of the study population by resident is shown in Table 1. Most of cases were from North followed by West and Centre constituting 13/40 (32.5\%), 12/40 (30\%), 12/40 (30\%), respectively.

Table 2 summarizes the results of High Risk (HR-HPV) with other demographical factors. Of the 40 cases, HRHPV 16, 18 were identified in 16/40 (40\%), of the cervical tissues of whom 8/16 (50\%) were positive for HPV 16; 6/16 (37.5\%) were identified with HR-HPV 18, and 2/16 (12.5\%) were detected with both HR-HPV subtypes, as indicated in Table 2, Photomicrograph1 (Figure 2). All of the clinically healthy cases were found negative. Only one oral tissue sample (case) out of $40(1 / 40=2.5 \%)$ was found
Table 2 Distribution of study population by age and

\begin{tabular}{lccccccc} 
Variable & Category & \multicolumn{2}{c}{ Cases } & & \multicolumn{2}{c}{ Controls } & Total \\
\cline { 3 - 4 } & & No & $\%$ & & No & $\%$ & \\
\hline Age & $18-25$ & 8 & 20 & 3 & 30 & 11 \\
& $26-35$ & 21 & 52.5 & 5 & 50 & 26 \\
& $36-45$ & 6 & 15 & 1 & 10 & 7 \\
& $46-70$ & 5 & 12.5 & 1 & 10 & 6 \\
\multirow{4}{*}{ Resident } & Total & 40 & 100 & 10 & 100 & 50 \\
& North & 13 & 32.5 & 4 & 40 & 17 \\
& West & 12 & 30 & 2 & 20 & 14 \\
& East & 3 & 7.5 & 0 & 0 & 3 \\
& Center & 12 & 30 & 4 & 40 & 16 \\
& Total & 40 & 100 & 10 & 100 & 50 \\
\hline
\end{tabular}

positive for HPV subtype 16. According to age, a high rate of infection with HR-HPV 16 was observed in among age group 18-26 years representing 4/8 (50\%) followed by age range $26-35$ representing 3/8 (37.5\%). For infection with HR-HPV 18, the highest frequency was detected among age group 3/6 (50\%) followed by age range 36-45 years constituting $2 / 6(33.3 \%)$. The $2 / 2(100 \%)$ cases infected with both HR-HPV $16 \& 18$ were found among age range 46-70 years, as shown in Table 3, Figure 3. According to the residence high frequencies of infection with HR-HPV 16 were found among patients from Northern Sudan representing $5 / 8$ (62.5\%) followed by Western Sudan 2/8 (25\%), similarly, high frequencies of infection with HRHPV 18 were seen among patients from Northern Sudan representing 5/6 (83.3\%). Infections with both HR-HPV 16 \& 18 were detected in two patients from Western Sudan, as seen in Table 3, Figure 4.

\section{Discussion}

Worldwide, after breast cancer, cervical cancer is the second most common cancer that affects women. In 99.7\% of all cases, cervical cancer results from a history of persistent infection by HR-HPV [5]. The high risk

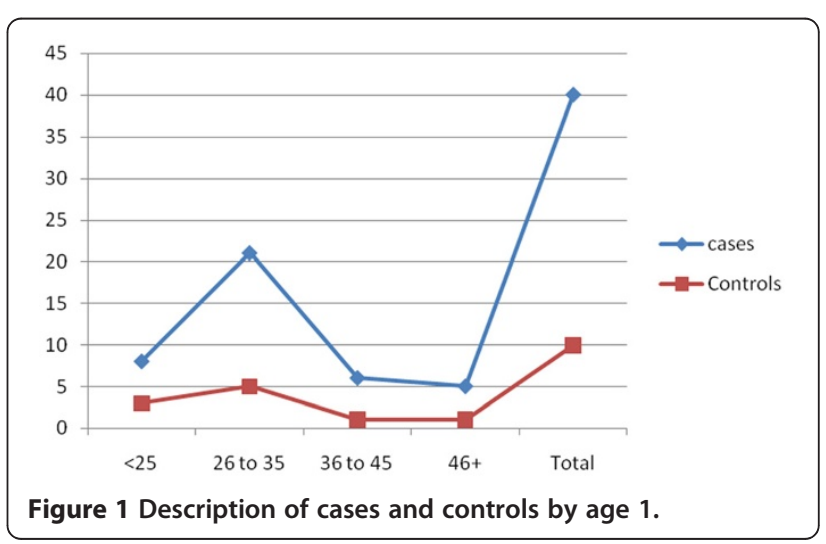




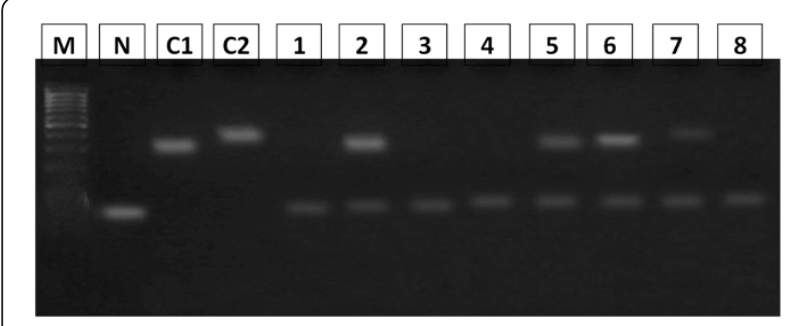

Figure 2 Photomicrograph 1. Ethidium bromide stained agarose gel 2\% electrophoresis of HPV PCR products, carried out on DNA samples extracted from fresh cells, Lane M:100 bp ladder, (Arrows shows 300 and 400 band), Lane N negative control, Lane C1 positive control for HPV16, Lane C2 positive control for HPV18,Lane 1-2-3-45-6-7-8 extracted DNA samples.

types occurring most frequently in cervical cancer include HPV-16 and HPV-18; together these account for over $70 \%$ of SCCs [18]. HPV-18 is also thought to account for approximately $50 \%$ of all adenocarcinomas [19]. Therefore, the present study mainly screened cervical and oral cells for the presence of these two HRHPV subset.

HPV infection rates vary greatly between geographic regions and population groups [20,21]. In the present study, HR-HPV 16 and 18 were identified in $40 \%$ of the cervical specimens. In a meta-analysis which was performed on studies published between 1995 and 2009 that used polymerase chain reaction or Hybrid Capture 2 for HPV detection in women with normal cytological findings. The analysis included 194 studies comprising $1,016,719$ women with normal cytological findings. The estimated global HPV prevalence was 11.7\% (95\% confidence interval, 11.6\%-11.7\%). Sub-Saharan Africa (24.0\%), Eastern Europe (21.4\%), and Latin America (16.1\%) showed the highest prevalences. Among the women with type-specific HPV data $(n=215,568)$, the 5 most common types worldwide were HPV-16 (3.2\%), HPV-18 (1.4\%),

Table 3 Distribution of cases according to HPV DNA detection in cervical cells

\begin{tabular}{lccccccc}
\hline Variable & category & \multicolumn{2}{c}{ HR-HPV $\mathbf{1 6}$} & \multicolumn{2}{c}{ HR-HPV $\mathbf{1 8}$} & HR-HPV & $\mathbf{1 6} \& \mathbf{1 8}$ \\
\hline \multirow{4}{*}{ Age } & & +ve & -ve & +ve & -ve & +ve & -ve \\
& $18-25$ & 4 & 4 & 0 & 8 & 0 & 8 \\
& $26-35$ & 3 & 18 & 3 & 18 & 0 & 21 \\
& $36-45$ & 1 & 5 & 2 & 4 & 0 & 6 \\
\multirow{4}{*}{ Resident } & $46-70$ & 0 & 5 & 1 & 4 & 2 & 5 \\
& Total & 8 & 32 & 6 & 34 & 2 & 40 \\
& North & 5 & 8 & 5 & 8 & 0 & 13 \\
& West & 2 & 10 & 1 & 11 & 2 & 10 \\
& East & 0 & 3 & 0 & 3 & 0 & 3 \\
& Center & 1 & 11 & 0 & 12 & 0 & 12 \\
& Total & 8 & 32 & 6 & 34 & 2 & 38 \\
\hline
\end{tabular}

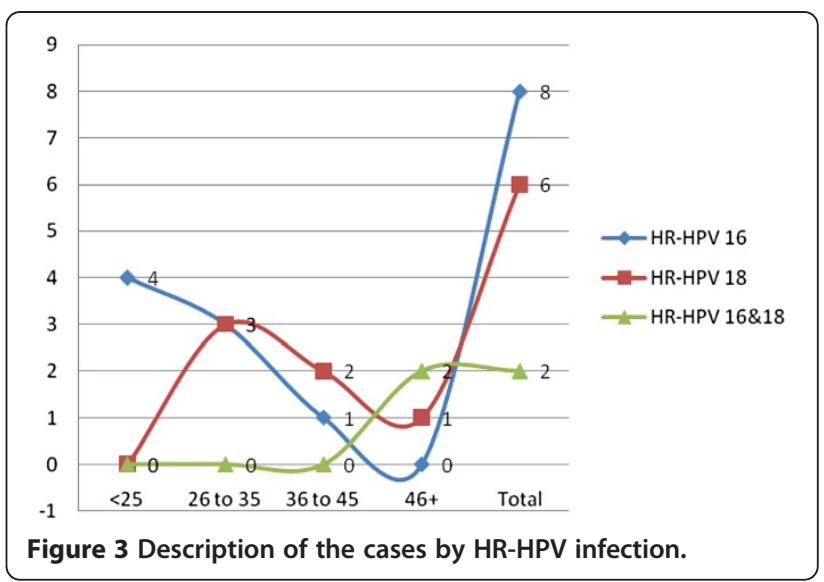

HPV-52 (0.9\%), HPV-31 (0.8\%), and HPV-58 (0.7\%) [22]. Prevalence of cervical HPV infection in most African countries is very high. HPV was detected in $100 \%$ of cervical biopsies from 70 women with cervical cancer in Papua New Guinea, with HPV types 16 and 18 being the most prevalent at $57.1 \%$ and $25.7 \%$ (95\% CI, $0.45-0.68$ and $0.17-0.37)$ respectively [23]. High frequencies of HR-HPV 18 and 16 were reported from Egypt [24], Morocco [25], $59 \%$, 56\% respectively. The only one study from Sudan, has reported $60.7 \%$ ß. globin positive samples for HPV indicating DNA integrity [26]. The authors analyzed HPV by general primer GP5+/6+ mediated PCR enzyme immunoassay (EIA) as described by Jacobs et al. [27] that its used to detect a broad spectrum of human papilloma virus (HPV) genotypes including the high-risk groups (HPV$16,18,31,33,35,39,45,51,52,56,58,59,66,68$ and 73) and low risk groups (HPV-6,11,40,42,43 and 44). Interestingly, the most common high risk infection in their study group was type 58, and in the low risk type 42.

In regard to age, most of positive cases were relatively observed among younger women, and these findings were consistent with global reports [28]. However, a

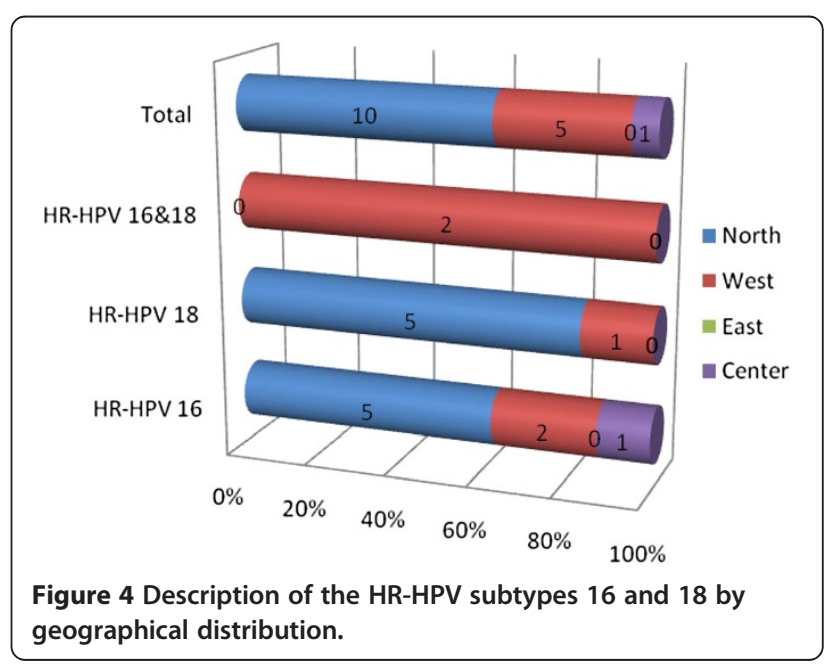


meta-analysis have reported age-specific HPV distribution presented with a first peak at younger ages ( $<25$ years) and, in the Americas and Africa, a rebound at older ages ( $\geq 45$ years) [22].

According to the residence, most of cases were from Northern Sudan. However, this might be due to the fact that Northern Sudan consist the most civilized part of the Sudan, this in addition to the fact the study was performed in the Northern Sudan.

In this study, oral HPV infection was found to be very low prevalent (2.5\%) than cervical HPV infection (40\%). Most women with an oral HPV infection also had a cervical infection, likely because the majority of women had a cervical infection. The increased prevalence of oral infections in women with simultaneous cervical infections would suggest that the behaviors that place a woman at risk for oral HPV infection could substantially overlap with cervical infection. Anogenital HPV infections in adults are predominantly sexually transmitted [29], and indeed, sexual behaviors have been previously associated with oral HPV infection [30]. Concomitant type-specific infections at both anatomic sites could be obtained during the same sexual encounter or sequential sexual encounters with an infected partner or autoinoculation from one site to the other [31]. However, only one study from the Sudan in this context has evaluated the possible role of high risk Human Papilloma viruses (HPV) 16 and 18 in oral squamous cell carcinomas (OSCC). HPVDNA was detected in $15 \%$ of cases (six out of 40 cases), and none of controls $(n=15), P<0.0001$ [32].

\section{Conclusion}

HR-HPV types 16 and 18 are the most commonly detected in Sudan and relatively similar to those described in neighboring African countries, although the relative contribution of HPV16 and HPV18 is substantially lower in cytologically normal women. The oral and cervical infection for HPV infection are likely independent of one another. Further more comprehensive studies are recommended for stronger clarification of association between HPV infection and cervical cancer in Sudan.

\section{Competing interests}

The authors declare that they have no competing interests.

\section{Authors' contributions}

AME: involved in the practical work (PCR). AHSED: involved in the practical work (PCR). RAHA: Patients management. HGA: consultation and Manuscript preparation. All authors read and approved the final manuscript.

\section{Author details}

${ }^{1}$ Department of Histopathology and cytology, University of Khartoum, Khartoum, Sudan. ${ }^{2}$ Department of Histopathology and cytology, FMLS, Sudan University for Science and Technology, Khartoum, Sudan.
${ }^{3}$ Department of Gynecology and Obstetrics, Omdurman Hospital, Omdurman, Sudan.

Received: 27 February 2012 Accepted: 2 July 2012

Published: 31 July 2012

\section{References}

1. Zachary R: Self-Collection and HPV DNA Testing Could Be an Effective Cervical Cancer Screening Method. J Natl Cancer Inst 2012, doi:10.1093/ jnci/djs029.

2. Hamad HMA: Cancer initiatives in Sudan. A symposium article. Annals of Oncology 2006, 17(8):832-836.

3. Ferlay J, Shin HR, Bray F, Forman D, Mathers C, Parkin DM: GLOBOCAN 2008, Cancer Incidence and Mortality Worldwide: IARC CancerBase No. 10 [Internet]. Lyon, France: International Agency for Research on Cancer; 2010. Available from: http://globocan.iarc.fr.

4. International Agency for Research on Cancer: IARC monographs on the evaluation of carcinogenic risks to humans: Volume 64 - human papillomavirus, 64. Lyon, France: IARC; 1995.

5. Walboomers JMM, Jacobs MV, Manos MM, et al: Human papillomavirus is a necessary cause of invasive cancer worldwide. J Pathol 1999, 189(1):12-19.

6. National Centre for Immunization Research \& surveillance: Human papillomavirus (HPV) vaccines for Australians. In NCIRS Fact sheet 2010:1-7.

7. Muñoz N, Bosch FX, de Sanjosé S, et al: Epidemiologic classification of human papillomavirus types associated with cervical cancer. $N$ Engl J Med 2003, 348:518-527.

8. Bernard $\mathrm{HU}$ : The clinical importance of the nomenclature, evolution and taxonomy of human papillomaviruses. J Clin Virol 2005, 32:1-6.

9. Hjazović E, Mustadenagić MJ, Cickusić E, Avdić S: Presence of high risk human papilloma viruses (HPV) in the low grade cervical lesion. Med Arh 2006, 60(1):30-32.

10. Chaudhary AK, Singh M, Sundaram S, Mehrotra R: Role of human papillomavirus and its detection in potentially malignant and malignant head and neck. Head Neck Oncol 2009, 1(1):22.

11. Tachezy R, Klozar J, Rubenstein $L$, et al: Demographic and risk factors in patients with head and neck tumors. J Med Virol 2009, 81(5):878-87.

12. Silva KC, Rosa ML, Moyse N, Afonso LA, Oliveira LH, Cavalcanti SM: Risk factors associated with human papillomavirus infection in two populations from Rio de Janeiro, Brazil. Mem Inst Oswaldo Cruz 2009, 104(6):885-91.

13. Hassan FM, Khirelseed M: Cervical Cancer Screening among Sudanese Women. Gulf J Oncolog 2009, 6:28-34.

14. Husain N, Helali T, Domi M, Bedri S: Cervical cancer in women diagnosed at the National Health Laboratory. Sudan: A call for screening 2011, 6(3):183-190.

15. Ibrahim A, Rasch V, Pukkala E, Arja RA: Cervical cancer risk factors and feasibility of visual inspection with acetic acid screening in Sudan. Int J Womens Health 2011, 3:117-122.

16. Ibrahim SO, Bertelsen B, Kalvenes MB, et al: Expression of keratin 13, 14 and 19 in oral squamous cell carcinomas from Sudanese snuff dippers: lack of association with human papillomavirus infection. APMIS 1998, 106(10):959-69.

17. Ibrahim SO, Warnakulasuriya KA, Idris AM, Hirsch JM, Johnson NW, Johannessen AC: Expression of keratin 13, 14 and 19 in oral hyperplastic and dysplastic lesions from Sudanese and Swedish snuff-dippers: association with human papillomavirus infection. Anticancer Res 1998, 18(1B):635-645.

18. Munoz N, Bosch FX, Castellsague $X$, et al: Against which human papillomavirus types shall we vaccinate and screen? The international perspective. Int J Cancer 2004, 111(2):278-285.

19. Royal College of Nursing: Human papilloma virus ( HPV) and Cervical Cancer. London: RCN; 2006. Available from http://www.rcn.org.uk/_data/assets/ pdf_file/0011/78716/003083.pdf.

20. Syrjänen K, Hakama M, Saarikoski S, et al: Prevalence, incidence, and estimated life-time risk of cervical human papillomavirus infections in a non-selected Finnish female population. Sex Transm Dis 1990, 17:15-19.

21. Koutsky L: Epidemiology of genital human papillomavirus infection. Am J Med 1997, 102(5A):3-8.

22. Bruni L, Diaz M, Castellsagué X, Ferrer E, Bosch FX, de Sanjosé S: Cervical human papillomavirus prevalence in 5 continents: meta-analysis of 1 
million women with normal cytological findings. J Infect Dis 2010, 202(12):1789-99.

23. Tabone T, Garland SM, Mola G, O'Connor M, Danielewski J, Tabrizi SN: Prevalence of human papillomavirus genotypes in women with cervical cancerin Papua New Guinea. Int J Gynaecol Obstet 2012, Feb 9 [Epub ahead of print].

24. Abd El-Azim S, Lotfy M, Omr A: Detection of human papillomavirus genotypes in cervical intraepithelial neoplasia and invasive cancer patients. Clin Lab 2011, 57(5-6):363-371. Sharkia Governorate, Egypt.

25. Khair MM, Mzibri ME, Mhand RA, et al: Molecular detection and genotyping of human papillomavirus in cervicalcarcinoma biopsies in an area of high incidence of cancer from Moroccan women. $J$ Med Virol 2009, 81(4):678-84.

26. Magdi M S, Safi ME, Keith H, Khater T, Ishag A: Genotypes of human papilloma virus in Sudanese women with cervical pathology. Infectious Agents and Cancer 2010, 5:26.

27. Jacobs MV, de Roda Husman AM, van den Brule AJ, Snijders PJ, Meijer CJ, Walboomers JM: Group-specific differentiation between high- and lowrisk human papillomavirus genotypes by general primer-mediated PCR and two cocktails of oligonucleotide probes. J Clin Microbiol 1995, 33(4):901-905.

28. De Sanjosé S, Diaz M, Castellsagué X, et al: Worldwide prevalence and genotype distribution of cervical human papillomavirus DNA in women with normal cytology: a meta-analysis. Lancet Infect Dis 2007, 7(7):453-9.

29. Bosch F, Lorincz A, Munoz N, Meijer C, Shah K: The causal relation between human papillomavirus and cervical cancer. J Clin Pathol 2002, 55:244-265.

30. Kreimer AR, Alberg AJ, Daniel R: Oral human papillomavirus infection in adults is associated with sexual behavior and HIV serostatus. I Infect Dis 2004, 189:686-698.

31. Carole F, Gypsyamber D, Elizabeth S: Relationship between Prevalent Oral and Cervical Human Papillomavirus Infections in Human Immunodeficiency Virus-Positive and -Negative Women. J Clin Microbiol 2006, 44(12):4479-4485.

32. Ahmed HG, Eltoom FM: Detection of Human Papilloma virus Types 16 and 18 among Sudanese patients with oral squamous cell carcinoma. The Open Cancer Journal 2010, 3:1-5.

doi:10.1186/1750-9378-7-17

Cite this article as: Elasbali et al: Cervical and Oral Screening for HR-HPV types 16 and 18 among Sudanese Women Cervical Lesions. Infectious Agents and Cancer 2012 7:17.

\section{Submit your next manuscript to BioMed Central and take full advantage of:}

- Convenient online submission

- Thorough peer review

- No space constraints or color figure charges

- Immediate publication on acceptance

- Inclusion in PubMed, CAS, Scopus and Google Scholar

- Research which is freely available for redistribution

Submit your manuscript at www.biomedcentral.com/submit
(O) Biomed Central 